\title{
The nutritional status of older Rwandan refugees
}

\author{
Simone Pieterse ${ }^{*}$, Mary Manandhar and Suraiya Ismail \\ Public Health Nutrition Unit, London School of Hygiene and Tropical Medicine, 49/51 Bedford Square, \\ London WCIB 3DP, UK
}

Submitted 14 August 1998: Accepted 24 August 1998

\begin{abstract}
Objective: To assess the nutritional status of older people in an unstable situation. Design: Anthropometric and socioeconomic data were collected cross-sectionally. Body mass index (BMI), arm muscle area (AMA) and arm fat area (AFA) were calculated to evaluate nutritional status. For 41 subjects with kyphosis, height was estimated from arm span using sex-specific regression equations from the nonkyphotic group.

Setting: The study was carried out in the post-emergency phase in a Rwandan refugee camp in Karagwe district, north-west Tanzania.

Subjects: Measurements were obtained from 413 men and 415 women aged 50-92 years. Results: The prevalence of undernutrition (BMI < 18.5) was $19.5 \%$ in men and $13.1 \%$ in women and was higher above age 60 years in both sexes: in men the prevalences were $23.2 \%$ and $15.0 \%(P<0.05)$ and in women $15.1 \%$ and $10.9 \%$ for the older and younger age groups respectively. AMA, which is important in relation to the ability to remain active and independent, was also significantly lower in older age groups. No difference was found in AFA. The proportion with low BMI was much higher in the group with kyphosis.

Conclusions: Even in this population of older Rwandans who managed to reach the camp and survive in exile for more than a year, undernutrition does occur and is more prevalent at an advanced age. The higher prevalence of undernutrition in kyphotic people illustrates the importance of including this group in nutritional status assessments.
\end{abstract}

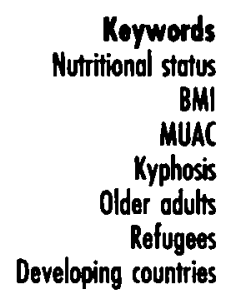

There is evidence of a worldwide demographic transition'. People not only live longer, but the proportion of older people in the population is also growing. Ageing is not confined to the developed world: already the majority of the world's older people live in developing countries and this proportion is expected to increase to nearly $80 \%$ by 2020 . Moreover those above 80 years of age are the fastest growing part of the world's older populations ${ }^{2}$. Considering the living conditions of the majority in developing countries, these older people can be expected to have many nutritional and health problems that will adversely affect their quality of life and ability to carry out daily tasks independently ${ }^{3}$. Although a growing number of studies include older people in developing countries, there is still a relative lack of data ${ }^{4.5}$.

The number of refugees and internally displaced persons grew by $40 \%$ between 1990 and $1993^{\circ}$. War and civil strife are increasingly responsible for mass population displacements and food shortages affecting large numbers of civilians. In unstable situations, older people can be a particularly vulnerable group as living conditions are harsh and social networks may have broken down, yet consideration of older age groups in these situations is still rare. However, determining the risk of vulnerability to undernutrition amongst older adults may be a better indicator of a household's nutritional stress than levels of undernutrition in children alone. There is some evidence that older people forego their food ration in favour of relatives and in Bosnia-Herzegovina undernutrition was found to be absent among children whereas the prevalence in older adults was $10-20 \%{ }^{7}$.

\section{Subjects and methods}

\section{Etbical aspects}

The data collection took place between December 1995 and June 1996 under the umbrella of HelpAge International (Tanzania), a non governmental organization (NGO) that had been working locally with older refugees since mid 1994. The majority of the 
Table 1 Regression equations

\begin{tabular}{|c|c|c|c|c|c|c|c|c|c|c|}
\hline & & & & & & & $r$ & $R^{2}$ & $\overline{\text { SEE }}$ & $\bar{n}$ \\
\hline $\begin{array}{l}\text { Men } \\
\text { Women }\end{array}$ & $\begin{array}{l}\text { height }= \\
\text { height }=\end{array}$ & $\begin{array}{l}0.69 \\
0.68\end{array}$ & $\begin{array}{l}\text { arm span } \\
\text { arm span }\end{array}$ & $\begin{array}{l}+42.34 \\
+49.55\end{array}$ & -0.08 & age & $\begin{array}{l}0.84 \\
0.84\end{array}$ & $\begin{array}{l}0.71 \\
0.70\end{array}$ & $\begin{array}{l}3.5 \\
3.4\end{array}$ & $\begin{array}{l}373 \\
387\end{array}$ \\
\hline
\end{tabular}

refugees had fled between April and September 1994, and although the situation was still unstable, it was no longer an emergency as the refugees were well established in the camp. Formal approval for this study was given by the United Nations High Commissioner for Refugees and the Ethics Committee of the London School of Hygiene and Tropical Medicine. Measurements were only obtained after participants had given their informed consent. Those in need of medical and/or social attention were referred to the appropriate NGOs.

\section{Age determination}

Age was determined by a series of questions about local and personal events. Where possible this was double checked with information from relatives, and from identity cards that had been issued in 1958 which many refugees were still carrying.

\section{Sampling and response rate}

A list of the camp's elderly population was compiled based on HelpAge International's camp register. This list, and the fact that households had addresses, enabled us to draw a random, stratified sample that ensured equal representation in terms of sex and age (above and below 60 years). The response rate was $85 \%$.

\section{Data collection and quality control}

The study took place in Chabalisa II refugee camp in Karagwe district, north-west Tanzania, and included 828 people aged $50-92$ years. A local team was recruited and trained in conducting a structured questionnaire addressing socio economic issues and taking a wide range of anthropometric measurements*. Intra- and inter-observer errors were calculated for anthropometric measurements and found to be small enough to achieve reliabilities of 0.98 and 0.99 , respectively ${ }^{8}$.

\section{Antbropometry}

Anthropometric measurements were taken twice according to standard techniques, except the triceps skinfold which was taken in triplicate ${ }^{9-11}$. The results of only a selection of measurements will be presented: weight, height, mid-upper arm circumference (MUAC) and triceps skinfold. Anthropometric variables were used to calculate the following derived variables: body mass index (BMI), upper-arm muscle area corrected for bone mass according to sex (AMA) and upper-arm fat area (AFA $)^{8,12}$. The presence of oedema and kyphosis were diagnosed visually by a nurse.

\section{Derivation of BMI}

The BMI calculation poses problems when a reliable height measurement cannot be obtained due to spinal curvature or poor muscle tone ${ }^{13,14}$. Therefore height was estimated from long bone measurements (knee height, arm span, half $\operatorname{span}^{\dagger}$, demi span ${ }^{\ddagger}$ ). Sex-specific regression equations were obtained for height versus each alternative measurement, using the non-kyphotic group. As this does not account for invisible height loss due to spinal compression, and as the 'older old' may have shrunk more than the 'younger old', age was also entered into the equations. However, age made no significant contribution in equations with arm measurements in men.

Arm span proved to be the best practical alternative to height. Hence height was estimated from arm span (and age in women) for the kyphotic group, using the regression equations in Table 1 . Thus BMI was calculated either using height, or height estimated from arm span when height could not be measured accurately.

\section{Indicators of undernutrition and their classiffication}

BMI cut-offs of 18.5 and 16 were used to define undernutrition and severe undernutrition, respectively ${ }^{15}$. MUAC cut-offs of 23 and $22 \mathrm{~cm}$ were used for men and women respectively ${ }^{16}$.

\section{Statistical analysis}

Data were entered and analysed with the statistical programme SPSS/PC+ version 5.0 and its data entry package $^{17}$. Differences between the sexes and age groups were assessed by a $t$-test for equality of unrelated means for continuous variables. Equality of variances was tested with Levene's test as required when applying the $t$-test ${ }^{18}$. Triceps and AFA variables had to be transformed to obtain normal distributions. A chi-square test was used for categorical variables. Differences between more than two age groups were

\footnotetext{
- Physical and self-reported functional ability assessments were conducted but are not reported in this article.

$t$ The distance measured from the sternal notch to the tip of the middle finger.

The distance measured from the sternal notch to the root of the middle finger.
} 
Table 1 Means and so of anthropometric variables by age and sex ( 413 men, 415 women)

\begin{tabular}{|c|c|c|c|c|c|c|c|c|c|}
\hline & \multirow[b]{2}{*}{ Sex } & \multicolumn{2}{|c|}{ All } & \multicolumn{2}{|c|}{$50-59$ years } & \multicolumn{2}{|c|}{$60-69$ years } & \multicolumn{2}{|c|}{$\geq 70$ years } \\
\hline & & Mean & SD & Mean & SD & Mean & SD & Mean & so \\
\hline Weight (kg) & $\begin{array}{l}M \\
F\end{array}$ & $\begin{array}{l}55.8 \\
52.5\end{array}$ & $\begin{array}{l}6.9 \\
7.6\end{array}$ & $\begin{array}{l}57.2 \\
54.4\end{array}$ & $\begin{array}{l}6.8 \\
8.1\end{array}$ & $\begin{array}{l}55.0^{*} \\
51.2^{*}\end{array}$ & $\begin{array}{l}6.8 \\
6.6\end{array}$ & $\begin{array}{l}54.1^{*} \\
49.9^{*}\end{array}$ & $\begin{array}{l}6.6 \\
6.6\end{array}$ \\
\hline Height (cm) & $\begin{array}{l}M \\
F\end{array}$ & $\begin{array}{l}166.1 \\
156.9\end{array}$ & $\begin{array}{l}6.6 \\
6.1\end{array}$ & $\begin{array}{l}167.2 \\
158.4\end{array}$ & $\begin{array}{l}6.4 \\
6.2\end{array}$ & $\begin{array}{l}165.7 \\
156.1^{*}\end{array}$ & $\begin{array}{l}6.5 \\
5.6\end{array}$ & $\begin{array}{l}163.9^{*} \\
154.3^{*}\end{array}$ & $\begin{array}{l}7.0 \\
5.9\end{array}$ \\
\hline BMI $\left(\mathrm{kg} \mathrm{m}^{-2}\right)^{\dagger}$ & $\begin{array}{l}M \\
F\end{array}$ & $\begin{array}{l}20.2 \\
21.3\end{array}$ & $\begin{array}{l}2.0 \\
2.9\end{array}$ & $\begin{array}{l}20.4 \\
21.7\end{array}$ & $\begin{array}{l}1.9 \\
3.1\end{array}$ & $\begin{array}{l}20.0 \\
21.0\end{array}$ & $\begin{array}{l}2.1 \\
2.6\end{array}$ & $\begin{array}{l}20.1 \\
21.2\end{array}$ & $\begin{array}{l}2.1 \\
2.7\end{array}$ \\
\hline $\operatorname{MUAC}(\mathrm{cm})$ & $\begin{array}{l}M \\
F\end{array}$ & $\begin{array}{l}25.1 \\
26.1\end{array}$ & $\begin{array}{l}1.9 \\
2.8\end{array}$ & $\begin{array}{l}25.5 \\
26.6\end{array}$ & $\begin{array}{l}1.8 \\
3.0\end{array}$ & $\begin{array}{l}24.9^{*} \\
25.8^{*}\end{array}$ & $\begin{array}{l}1.9 \\
2.6\end{array}$ & $\begin{array}{l}24.6^{*} \\
25.3^{*}\end{array}$ & $\begin{array}{l}2.1 \\
2.6\end{array}$ \\
\hline Triceps (mm) & $\begin{array}{l}\mathbf{M} \\
\mathbf{F}\end{array}$ & $\begin{array}{r}5.9 \\
11.8\end{array}$ & $\begin{array}{l}1.7 \\
4.2\end{array}$ & $\begin{array}{r}5.7 \\
12.2\end{array}$ & $\begin{array}{l}1.8 \\
4.4\end{array}$ & $\begin{array}{r}6.0 \\
11.6\end{array}$ & $\begin{array}{l}1.6 \\
4.0\end{array}$ & $\begin{array}{c}6.3^{*} \\
11.3\end{array}$ & $\begin{array}{l}1.9 \\
4.0\end{array}$ \\
\hline AMA $\left(\mathrm{cm}^{2}\right)$ & $\begin{array}{l}M \\
F\end{array}$ & $\begin{array}{l}33.2 \\
33.7\end{array}$ & $\begin{array}{l}6.3 \\
7.5\end{array}$ & $\begin{array}{l}34.7 \\
35.1\end{array}$ & $\begin{array}{l}6.0 \\
7.8\end{array}$ & $\begin{array}{l}32.3^{*} \\
33.0^{*}\end{array}$ & $\begin{array}{l}6.2 \\
7.1\end{array}$ & $\begin{array}{l}30.9^{*} \\
31.5^{*}\end{array}$ & $\begin{array}{l}6.4 \\
6.7\end{array}$ \\
\hline AFA $\left(\mathrm{cm}^{2}\right)$ & $\begin{array}{l}M \\
F\end{array}$ & $\begin{array}{r}7.2 \\
14.6\end{array}$ & $\begin{array}{l}2.4 \\
6.4\end{array}$ & $\begin{array}{r}7.1 \\
15.4\end{array}$ & $\begin{array}{l}2.5 \\
7.0\end{array}$ & $\begin{array}{r}7.2 \\
14.1\end{array}$ & $\begin{array}{l}2.2 \\
5.8\end{array}$ & $\begin{array}{r}7.5 \\
13.5\end{array}$ & $\begin{array}{l}2.7 \\
5.6\end{array}$ \\
\hline
\end{tabular}

- Means significantly different from those $50-59$ years, $P<0.05$.

† BMI calculated using height estimated from arm span for people with spinal curvature.

tested by one-way analysis of variance for continuous variables, using the $b$-tukey test to determine which groups differed significantly. Correlations were investigated by computing Pearson's Product Moment correlation coefficients. A statistical probability of $<0.05$ was considered significant.

\section{Results}

\section{Description of the sample}

The vast majority (97\%) of the sample came from villages in Rukara and Kigarama, both rural communes in East Rwanda. Educational status was quite low: $71 \%$ were illiterate, $8 \%$ had received adult or informal education and only $21 \%$ were formally educated. The majority (63\%) had been small farmers in Rwanda (owning land, and a few cattle), the rest were richer farmers owning both land and livestock.

In the camp, nearly $60 \%$ of the sample lived in some form of partnership ( $73 \%$ were men, $27 \%$ were women). The rest (40\%) lived without a partner $(16 \%$ were men, $84 \%$ were women). Thirty-five per cent of the population were widowed of whom $83 \%$ were female. The basic food basket - regularly provided by the World Food Programme - comprised maize (whole grain or meal), beans, corn soy blend, cooking oil and salt. Its nutritional value was increased from 8100 to $8996 \mathrm{~kJ}$ at the end of 1995 . The older refugees were still quite active in the camp. More than $70 \%$ were engaged in work in kitchen gardens and light household activities and $42 \%$ in heavy household activities such as fetching water and firewood.

- Civil or traditional marriage, remarried, living together but unmarried.

\section{Antbropometric characteristics by sex and age}

Table 2 summarizes the means and standard deviations of the anthropometric variables and statistical differences between age groups. Men had higher mean values than women for weight and height, but women exceed men for MUAC, triceps, skinfold, AMA, AFA and BMI. T-tests indicated significant differences between men and women for all variables except AMA $(P<0.001)$.

Comparing means across age groups, all variables except BMI and AFA, and triceps in women, show significantly lower means in older age groups. Muscle tissue is important in relation to the ability to carry out activities and remain independent and fat stores serve as an energy reserve. Table 2 shows that AMA is significantly lower in the older age groups in both sexes.

In addition to the 828 subjects there were 64 subjects with oedema. As this condition can have implications for weight, skinfold and circumference measurements, this group was analysed separately. Visible spinal curvature (kyphosis) was observed in 41 of the 828 subjects $(5 \%)$. There were no significant sex differences in prevalence of kyphosis and oedema, but prevalences were considerably higher in the oldest age group. People with oedema were compared with those without. As oedema mainly occurred in the legs, only anthropometric measurements on the arm were considered. Although results should be interpreted with caution, in men higher means for triceps and AFA were found in the group with oedema.

\section{Prevalence of undernutrition}

The proportions classified as undernourished according to $\mathrm{BMI}<18.5$ were $19.5 \%$ for men and $13.1 \%$ for 


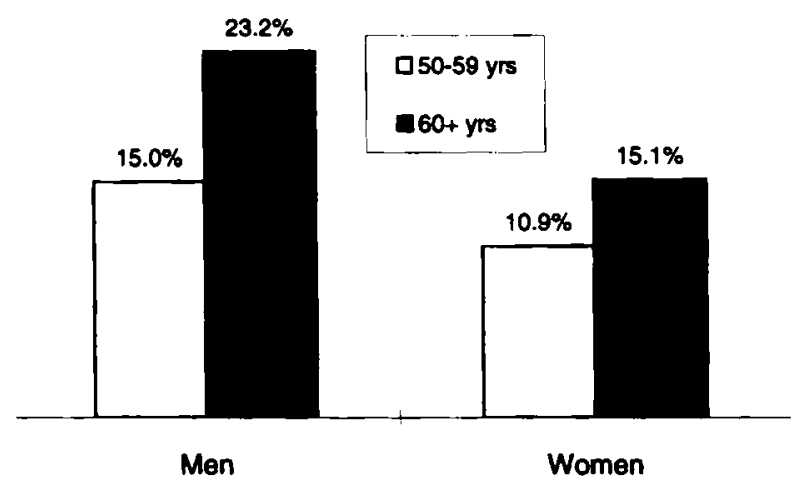

Fig 1 Percentage undernourished $(B M I<18.5)$ by age and sex.

women. Severely undernourished $(B M I<16)$ were $1.0 \%$ and $0.7 \%$, respectively. Figure 1 illustrates that the percentage undernourished was higher in older people ( $P<0.05$ in men).

Undernutrition was more prevalent in people with kyphosis. In kyphotic men $45.5 \%$ was undernourished (BMI < 18.5) compared with $18.0 \%$ in non-kyphotic men. In women the prevalence of undernutrition was $28.6 \%$ in the kyphotic group compared with $12.6 \%$ in the non-kyphotic group.

MUAC is an indicator of undernutrition that can be obtained quickly and with few resources. Using the cutoff points of $23 \mathrm{~cm}$ for men and $22 \mathrm{~cm}$ for women as proposed by James et al. ${ }^{16}, 10.2 \%$ of the men and $3.4 \%$ of the women were undernourished.

Applying the cut offs to MUACs of people with kyphosis, $20.8 \%$ of the kyphotic men had a low MUAC compared with $9.5 \%$ in the non-kyphotic group. In women the proportions were $5.9 \%$ in the kyphotic group compared with $3.3 \%$ in the non-kyphotic group.

\section{Discussion}

The results of this study should be interpreted bearing

Table 3 Anthropometric means in older adults* from Malawi ${ }^{26}$, Rwanda and the USA ${ }^{8}$

\begin{tabular}{lcccc}
\hline & Sex & $\begin{array}{c}\text { Malawi } \\
(\mathrm{n}=284)\end{array}$ & $\begin{array}{c}\text { Rwandan } \\
\text { refugees } \\
(\mathrm{n}=828)\end{array}$ & $\begin{array}{c}\text { Black } \\
\text { Americans } \\
(\mathrm{n}=1669)\end{array}$ \\
\hline Weight $(\mathrm{kg})$ & M & 54.1 & 55.8 & 75.4 \\
& F & 49.0 & 52.5 & 73.5 \\
BMI $\left(\mathrm{kg} \mathrm{m}^{-2}\right)$ & M & 19.7 & 20.0 & 25.4 \\
MUAC $(\mathrm{cm})$ & F & 20.3 & 21.2 & 28.8 \\
& M & 25.0 & 25.1 & 31.7 \\
Triceps $(\mathrm{mm})$ & F & 25.9 & 26.1 & 32.5 \\
& M & 6.7 & 5.9 & 10.8 \\
AMA $\left(\mathrm{cm}^{2}\right)$ & F & 11.4 & 11.8 & 26.7 \\
& M & 31.5 & 33.2 & 54.6 \\
AFA $\left(\mathrm{cm}^{2}\right)$ & F & 32.0 & 33.7 & 40.3 \\
& M & NA & 7.2 & 16.7 \\
& F & NA & 14.6 & 38.9 \\
\hline
\end{tabular}

- Over 55 years of age for Malawi and over 50 years for the other populations. NA, not available. the following issues in mind. We are concerned with an older refugee population, but those who were worst off may have remained at home, never reached the camp or died shortly after arrival. Furthermore, food security was not particularly precarious in rural East Rwanda before the war so the nutritional status of the inhabitants can be assumed to have been reasonable before their departure for Tanzania. Finally, the study took place in the post emergency phase and HelpAge International had been present in the camp for more than a year, advocating for the interests of older people and providing support. These facts make it likely that the nutritional status of this particular refugee population was better than that of other populations at the height of an emergency, and better than amongst those who stayed behind in Rwanda.

It is known that differences in anthropometric variables exist between sexes, age groups and races ${ }^{19-21}$. However, due to the scarcity of anthropometric data on older Africans, comparison of these results with other studies will also refer to elderly people of other races. Comparisons are in fact dual: African versus nonAfrican and refugee versus non-refugee.

\section{Weight and BMI}

As expected, men in this sample were generally bigger and leaner than women. Comparing weight and BMI of both sexes to those of black elderly people included in the National Health and Nutrition Examination Surveys I and II of the USA, black Americans are found to be much heavier and fatter, mean weight in the 50-55 and $70-75$ years age groups ranging from 79.6 to $72.1 \mathrm{~kg}$ in men and from 77.6 to $69.5 \mathrm{~kg}$ in women ${ }^{8}$. Similar differences are seen for BMI. Means for Rwandan men and women (all ages) were 20.2 and 21.3 , respectively, whereas the lowest means for US men and women (age group 70-75 years) were 24.6 and 27.6, respectively. Mean BMI values in elderly people from several European towns ranged from 25.2 to 27.4 in men and 23.9 to 28.6 in women ${ }^{22}$. These differences in body measurements presumably reflect better nutrition and higher living standards in the USA and Europe.

Ethangatta et al. ${ }^{23}$ studied 113 very poor and 88 low income women (aged 57-74 years) living in Nairobi. The mean weights in these groups were $55 \mathrm{~kg}$ for very poor and $64 \mathrm{~kg}$ for low income women with mean BMIs of $23 \mathrm{~kg} \mathrm{~m}^{-2}$ and $26 \mathrm{~kg} \mathrm{~m}^{-2}$, respectively. The present results of the refugee women (see Table 3) were lower than those of the Nairobi women, but all were very similar to rural Gambians (60-85 years) ${ }^{24}$. Unfortunately, some of the other studies did not make explicit what was done in cases of kyphosis. Ordinary height may have been used in the BMI resulting in an overestimation. Some studies excluded kyphotic people, which may have resulted in exclusion of the worst cases. 
A recent survey among Saharawi refugees in Algeria gave BMI figures for adults over 60 years with height estimated from half span based on regression equations from younger adults in the same population ${ }^{25}$. Undernutrition amounted to $25.0 \%$ in men and $11.5 \%$ in women. Severely undernourished were $4.2 \%$ and $3.3 \%$, respectively. The proportions of severely undernourished people and undernourished men were higher in Saharawi refugees compared to the Rwandan refugees. Possible explanations are given above in the first paragraph of this section.

In a study among older people in rural Malawi ${ }^{26}, \mathrm{BMI}$ was calculated in the same way as in the present study. Interestingly, the Malawians had lower mean weights and BMIs than the Rwandan refugees (Table 3). Also, the prevalence of low BMI $(<18.5)$ was higher in Malawi: $36.1 \%$ for men and $27.0 \%$ for women. This may be explained by the fact that the refugees at least had access to regular basic food in the camp which is not always the case in stable low income communities.

The prevalence of low BMI among kyphotic people was much higher than among non-kyphotic people. This may partly be due to a higher mean age in the group with kyphosis ( 69.5 compared with 60.5 years). However, this cannot explain the large difference as the prevalence of undernutrition in the oldest nonkyphotic group ( $\geq 70$ years) was lower: $20.0 \%$ for men and $9.1 \%$ for women.

\section{Estimates of fat and muscle areas}

Refugee women had higher mean values for MUAC, AMA, triceps and AFA than men. Values for black American men and women were again much higher than those for the refugee population as shown in Table 3.

Ndaba \& O'Keefe ${ }^{27}$ surveyed 337 rural black South African pensioners of advanced mean age ( 78 years for men, 80 years for women). MUAC and uncorrected AMA values were very similar to those in the oldest group of Rwandan refugees (mean age 75 years).

The triceps skinfold was the only fat measure reported in the study on Malawi elderly and Nairobi women. The values for both sexes in the Malawi sample were close to those of the refugees (Table 3). However, the mean triceps thickness of female refugees of $11.8 \mathrm{~mm}$ was well below the figures of $16.9 \mathrm{~mm}$ for very poor and $21.8 \mathrm{~mm}$ for low income female Kenyan $\mathrm{s}^{23}$ and similar to a value of $12.2 \mathrm{~mm}$ in female rural Gambians ${ }^{24}$. This was also the case in male refugees and Gambians who had mean triceps of $5.9 \mathrm{~mm}$ and $6.4 \mathrm{~mm}$, respectively.

Refugee women had a significantly higher mean AFA than men which is a common sex difference. However, men did not have significantly more arm muscle tissue (adjusted for bone mass) than women. This is remarkable - although it also occurred in the Malawi sample - and cannot be explained by activity levels (men were significantly more frequently engaged in heavy household tasks and agricultural work on local farms than women).

It is possible that the sex-specific correction factor for bone mass is inappropriate for this ethnic group. However, sex differences in uncorrected AMA were also small in the refugees and black American women had a substantially lower mean corrected AMA than men. Table 3 shows that mean AMA in the refugee sample was higher than in the Malawi sample and mean AFA lower. However, all figures were substantially lower than those for black Americans.

\section{Classifying undernutrition in older people}

In the absence of validated BMI and MUAC cut-offs to classify undernutrition in older people ${ }^{4,5}$, cut-off points for adults proposed by Shetty \& James ${ }^{15}$ for BMI and by James et al. ${ }^{16}$ for MUAC were used. Because of changes in body composition, the validity and interpretation of these cut-offs for the elderly, particularly those over 70 years, are in question.

The proportions classified as undernourished using low MUAC were substantially smaller than those classified using low BMI. This was also seen in James et al's data ${ }^{16}$ and in the Malawi study ${ }^{26}$. These findings bring into question the validity of the MUAC cut-offs proposed by James et al. ${ }^{16}$ for rural African populations. These cut-offs are based on data from younger Third World adults and James' own data also show that rural Africans have higher MUAC values than rural Indians of similar age. This suggests that MUAC cut-offs (and/or BMI cut-offs) may need to be region- and/or age-specific.

\section{Conclusions}

This research proved that it is feasible to carry out a scientifically sound study in an unstable situation after the emergency phase. The results show that even in this self-selected population of relatively fit older Rwandans who managed to reach the camp and survive in exile for more than a year, undernutrition occurs and is more prevalent at advanced age.

The higher prevalence of undernutrition in kyphotic people also illustrates the importance of including this group in nutritional status assessments. This can be done by using long bone approximates of stature, such as arm span, as alternatives to height for people of whom height cannot be measured accurately. The equation to estimate height from arm span needs to be specific to the ethnic group in question, and should ideally be based on data from younger adults in the same population.

Priority is usually given to the conventionally vulnerable groups of young children and pregnant 
women, especially in unstable situations where resources are scarce. This overlooks the reality that many older adults in developing countries still play a valuable role within their families and wider communities. Their contributions may be even more crucial in conflict-induced unstable situations where families are divided and many young adults are absent or have died.

\section{Acknowledgements}

The Department for International Development (UK) was the main funder of this study. HelpAge International initiated and partly funded the study and provided logistical and other support in collaboration with HelpAge Tanzania. None of these organizations are responsible for the content of this article.

\section{References}

1 Gorman M. Older people and development: the last minority? Dev. Pract. 1995; 5: 117 -27.

2 Restrepo HE, Rozental $M$. The social impact of aging populations: some major issues. Soc. Sci. Med. 1994; 39: 1323-38.

3 Manandhar MC. Functional ability and nutritional status of free living elderly people. Proc. Nutr. Soc. 1995; 54: 677-91.

4 WHO. Physical Status: Use and Interpretation of Antbropometry. Tecbnical Report Series 854. Geneva: World Health Organization, 1995.

5 Onis $\mathrm{M}$ de, Habicht $\mathrm{J}$. Anthropometric reference data for international use: recommendations from a WHO Expert Committee. Food Nutr. Bull. 1997; 18: 179-89.

6 Toole MJ, Waldman RJ. Refugees and displaced persons. War, hunger, and public health. J. Am. Med. Assoc. 1993; 270: $600-5$.

7 Vespa J, Watson $\mathrm{F}$. Who are the nutritionally vulnerable in Bosnia-Herzegovina? Br. Med. J. 1995; 311: 652-54.

8 Frisancho AR. Anthropometric Standards for the Assessment of Growth and Nutritional Status. Ann Arbr: University of Michigan Press, 1990.

9 Lohman TG, Roche AF, Martorell R. Anthropometric Standardization Reference Manual. Champaign, Illinois: Human Kinetics, 1988.

10 Chumlea WC, Roche AF, Mukherjee D. Nutritional Assessment of the Elderly Through Anthropometry. Ohio: Fells Research Institute, Ross Laboratories, 1987.
11 Gibson RS. Principles of Nutritional Assessment. New York: Oxford University Press, 1990.

12 Heymsfield SB, McManus C, Smith J, Stevens V, Nixon DW. Anthropometric measurements of muscle mass: revised equations for calculating bone-free arm muscle areas. $\mathrm{Am}$. J. Clin. Nutr. 1982; 36: 680-90.

13 Borkan G, Hults D, Glynn R. Role of longitudinal change and secular trend in age differences in male body dimensions. Hum. Biol. 1983; 55: 629-41.

14 Chumlea $C$, Baumgartner R. Status of anthropometry and body composition data in elderly subjects. Am. J. Clin. Nutr. 1989; 50: 1158-66.

15 Shetty P, James W. BMI. A Measure of Chronic Energy Deficiency in Adults. Rome: Food Agriculture Organisation, 1994.

16 James WPT, Mascie-Taylor GCN, Norgan NG, Bistrian BR, Shetty PS, Ferro-Luzzi A. The value of arm circumference measurements in assessing chronic energy deficiency in Third World adults. Eur. J. Clin. Nutr. 1994; 48: 883-94.

17 SPSS Inc. Statistical Package for the Social Sciences, Version 6.0. Chicago, Illinois: SPSS Inc, 1993.

18 Norušis MJ. SPSS 6.1 Guide to Data Analysis. New Jersey Prentice Hall, 1991.

19 Chumlea WM, Roche AF, Mukherjee D. Some anthropometric indices of body composition for elderly adults. $J$. Gerontol. 1986; 41: 36-9.

20 Delarue J, Constans T, Malvy D, Pradignac A, Couet C, Lamisse F. Anthropometric values in an elderly French population. Br.J. Nutr. 1994; 71: 295-302.

21 Launer LJ, Harris T (on behalf of the Ad Hoc Committee on the Statistics of Anthropometry and Aging). Weight, height and BMI distributions in geographically and ethnically diverse samples of older persons. Age Ageing. 1996; 25: 300-6.

22 SENECA Investigators. Longitudinal changes in anthropometric characteristics of elderly Europeans. Eur.J. Clin. Nutr. 1996; 50: S9-S15.

23 Ethangatta LK, Gee MI, Hawrysh ZJ. Protein-energy malnutrition in low income elderly Nairobi women. Nat.J. Food Sci. Nutr. 1996; 47; 147-57.

24 Aspray TJ, Prentice A, James OFW. The nutritional status of elderly rural Gambians. Age Ageing. 1994; 23 : 48.

25 Branca F (unpublished report). The Nutritional Status and Nutritional Vulnerability of Sabarawi Refugees. Instituto Nazionale della Nutrizione, Italy, 1998.

26 Chilima D, Ismail S. Anthropometric characteristics of older people in rural Malawi. Eur. J. Clin. Nutr. (in press).

27 Ndaba N, O'Keefe SJD. The nutritional status of black adults in rural districts of Natal and Kwazulu. S. Afr. Med. J. 1985; 68: $588-90$. 